\title{
ABELHAS POLINIZADORAS DE PLANTAS COM ANTERAS PORICIDAS EM UMA ÁREA DE PRODUÇÃO ORGÂNICA
}

\author{
Mônica Mirzza Dultra-Correia ${ }^{1}$ e Miriam Gimenes ${ }^{2}$ \\ 1. Bolsista PIBIC/FAPESB, Graduanda em Agronomia, Universidade Estadual de Feira de Santana, e-mail: \\ dultramonica@gmail.com \\ 2. Orientadora, Departamento de Ciências Biológicas, Universidade Estadual de Feira de Santana, e-mail: \\ miriagimenes@gmail.com
}

PALAVRAS-CHAVE: abelhas; anteras poricidas; polinização.

\section{INTRODUÇÃO}

O processo de polinização é necessário para a produção de sementes e frutos, sendo assim, é um processo de importância para a vida humana. As abelhas são os polinizadores mais importantes, pois são as mais diversas e eficientes (Freitas e Soares, 2004). Muitas plantas de importância econômica, como tomate, batata, pimentão e berinjela dependem exclusivamente das abelhas para serem polinizadas, pois todas elas possuem flores com anteras poricidas. As anteras poricidas são características de algumas famílias botânicas como Solanaceae, da ordem Solanales, selecionada para o presente estudo. Este tipo de antera restringe o número de espécies de abelhas visitantes, e dependem daquelas que possuem a capacidade de vibrar as anteras através da musculatura torácica com frequências adequadas para a liberação do pólen, e assim, executar a polinização (Renner 1986/87, 1990 in Oliveira e Gimenes, 2004), como as abelhas das famílias Andrenidae, Apidae, Colletidae, Halictidae, Oxaeidae e Megachilidae (Nunes-Silva et al., 2010). Atualmente, a diminuição do número de abelhas por intoxicação por agrotóxico é um problema de escala mundial, que traz ameaças inclusive ao homem, causador desses problemas (Assis, 2014). É importante que haja o uso de práticas de manejo sustentável que diminuam os danos, uma alternativa para a manutenção dos polinizadores em área de cultivo é a agricultura orgânica que tem como objetivo a produção de alimentos sem o uso de substâncias como fertilizantes sintéticos solúveis, agrotóxicos e transgênicos que colocam em risco a saúde das pessoas e animais que ali vivem e também o meio ambiente. Este estudo teve como objetivo estudar as espécies de abelhas e seu trabalho de polinização nas plantas com anteras poricidas, verificando quais são as espécies mais frequentes e eficientes, em uma área de produção orgânica próxima de Feira de Santana/BA, a Chácara Bocaiúva, localizada no distrito de Humildes. O clima da região é o semiárido com temperatura média anual de $23,5^{\circ} \mathrm{C}$.

\section{MATERIAL E MÉTODOS}

As coletas e observações foram realizadas bimestralmente, das $7 \mathrm{~h} 00$ às $16 \mathrm{~h} 00$, durante um ano, por três dias, sendo dois dias para a realização das coletas e um dia para observações do comportamento dos visitantes florais. Para as coletas das abelhas foi utilizado o método de Sakagami et al. (1967) que consiste na coleta das abelhas com rede entomológica em cada planta florida por cinco a dez minutos, e depois passando para a próxima planta com antera poricida. Além da coleta das abelhas nas plantas com anteras poricidas, as abelhas também foram coletadas em flores de plantas (que não tinham anteras poricidas) que cresciam próximas as do objetivo do estudo. Devido ao pequeno número de plantas floridas na Chácara, foram confeccionadas armadilhas com garrafas PET para a coleta das abelhas nos meses de fevereiro, abril e junho/2016. Foram feitas armadilhas em dois modelos, armadilhas de água fazendo o uso de detergente (duas na cor azul, duas amarelas e três vermelhas) e, quatro armadilhas de odor, cada uma com um tipo de isca (acetato de benzila, vanilina, 
eucaliptol e beta ionona) embebido em algodão. As armadilhas foram penduradas por barbantes em árvores no interior da mata na Chácara (área naturalmente preservada), em cerca de $1,5 \mathrm{~m}$ de altura, nos três dias de visita em cada mês. As armadilhas eram colocadas às 07h00 e retiradas às 16h00. Os dados microclimáticos (temperatura e umidade relativa do ar) foram obtidos através de um termohigrômetro digital fixado a $1,5 \mathrm{~m}$ acima do solo e os dados referentes à intensidade luminosa (iluminância) foram obtidos com a utilização de um luxímetro, em intervalos de uma hora, durante as observações. Os dados macroclimáticos dos diferentes meses durante o ano de pesquisa foram obtidos através da estação meteorológica da UEFS, a estação mais próxima (Figura 1). Também foi feito um levantamento na literatura das abelhas visitantes e polinizadoras de plantas com anteras poricidas.

\section{RESULTADOS E DISCUSSÃO}

Havia poucas plantas com flores com anteras poricidas durantes os meses de visita, também foram coletadas abelhas em flores de plantas que cresciam próximas as do objetivo do estudo. As abelhas Trigona spinipes, Tetragonisca angustula e Apis mellifera foram as únicas abelhas vistas visitando as flores. Nas armadilhas de iscas de odor foram coletadas Trigona spinipes, Tetragonisca angustula, Euglossa cordata e Eulaema nigrita. T. spinipes foi a espécie mais frequente nas flores e nas iscas, mesmo existindo três caixas de T. angustula no local. Foram encontrados ninhos de $T$. spinipes na chácara, porém os ninhos construídos por essas abelhas são constantemente destruídos pelos trabalhadores do local, o que justifica a diminuição de abelhas desta espécie nas flores. As abelhas observadas nas plantas mantinham suas atividades diárias mais intensas durante a manhã, e conforme os dias iam passando e as flores ficavam velhas, o número de abelhas também diminuía. A média da temperatura nos horários de maior visita das abelhas nas flores, entre $07 \mathrm{~h} 00$ e $10 \mathrm{~h} 00$, esteve entre 22 e $24{ }^{\circ} \mathrm{C}$, a média da umidade relativa do ar esteve entre 34\% (dezembro/2015) e 75\% (outubro/2015).

Macroclimáticos

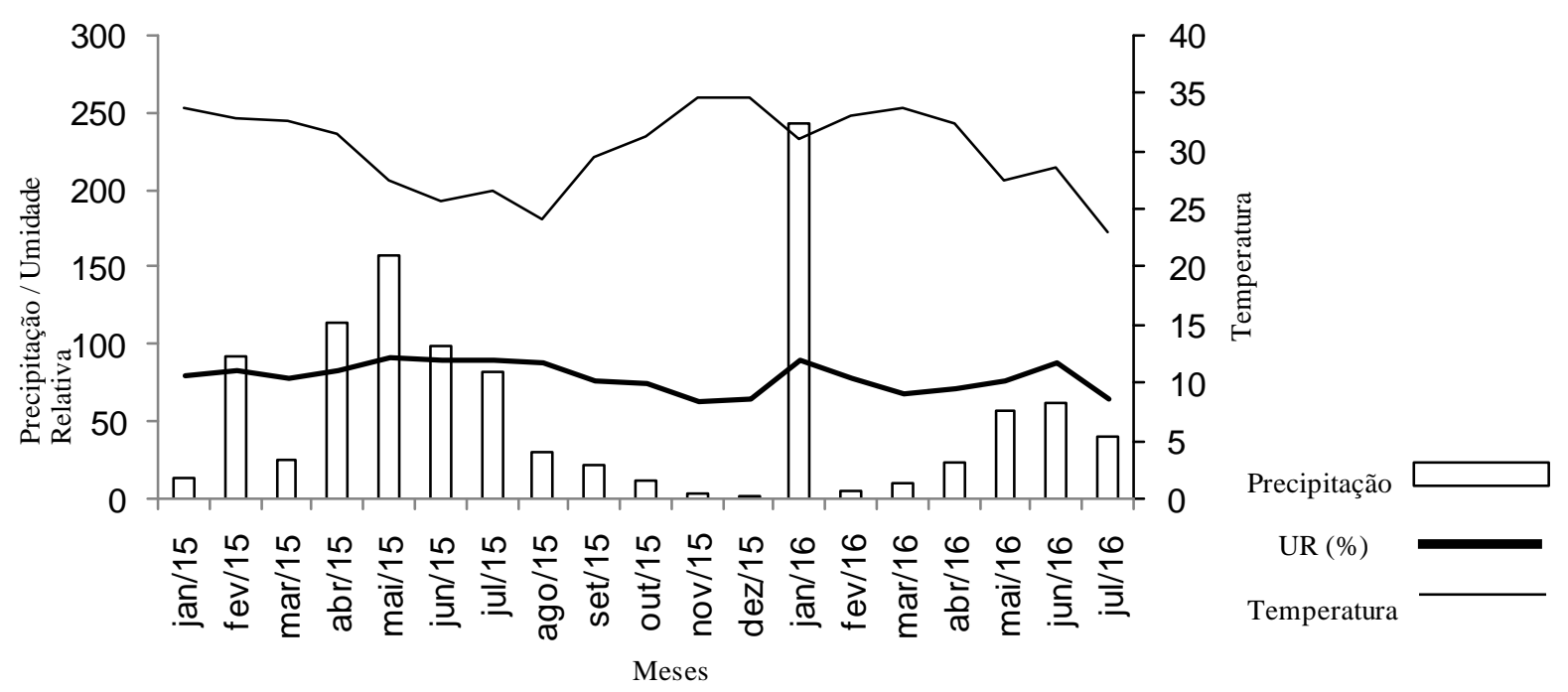

Figura 1. Média da temperatura $\left({ }^{\circ} \mathrm{C}\right)$ e umidade relativa em Feira de Santana de janeiro/2015 a junho/2016. Dados macroclimáticos obtidos na Estação Meteorológica da UEFS.

\section{CONSIDERAÇÕES FINAIS}

De acordo com Carvalho (2013), que também desenvolveu um estudo de abelhas polinizadoras na Chácara Bocaiúva, T. spinipes, T. angustula e A. mellifera, foram as espécies 
mais abundantes entre as 54 espécies de abelhas nas 70 espécies de plantas observadas por ela. Assim como no estudo de Carvalho, T. spinipes, T. angustula e A. mellifera foram as espécies mais observadas nas plantas. A espécie T. spinipes da subfamília dos meliponíneos, nativa do Brasil, apresenta grande potencial polinizador em muitas espécies de plantas. Porém, esta espécie também possui comportamentos considerados prejudiciais a muitas culturas, pois elas fazem buracos nas anteras com as mandíbulas, ou cortes em botões florais antes da floração para coletar pólen e néctar (Nogueira-Neto, 1962 in Silveira et al., 2009), prejudicando a floração e a frutificação da planta. Esta foi a espécie mais frequente em todas as plantas, sendo elas com anteras poricidas ou não, apesar da chácara possuir três caixas de T. angustula. Segundo Lopes (2010) a temperatura média ideal para o bom desenvolvimento do ninho é entre 30 e $35^{\circ} \mathrm{C}$, e este fator pode ter influenciado na pouca quantidade de abelhas no local, pois, nos dias de visitas, durante o horário de maior visita das abelhas nas flores a temperatura na chácara estava abaixo deste intervalo de temperatura. Apesar das abelhas adultas serem mais tolerantes às diferentes variações climáticas, suas crias são mais sensíveis, e o ninho é prejudicado. Neste estudo de campo na Chácara Bocaiúva era esperada uma quantidade muito maior de espécies de abelhas visitantes. Porém, como esta é uma área de manejo de culturas e replantio constante, isso pode prejudicar a conservação dos ninhos de abelhas solitárias no solo, e devido a esse frequente manejo, não houve muitas plantas com anteras poricidas com flor durante os meses de coleta.

\section{REFERÊNCIAS}

ASSIS, L. Polinizadores em risco de extinção são ameaças à vida do ser humano. Ministério do Meio Ambiente. 2014. Disponível em: <http://www.mma.gov.br/informma/item/9976polinizadores-em-risco-de-extinção-são-ameaças-à-vida-do-ser-humano $>$. Acesso em: abril 2015.

CARVALHO, D. M. Interação abelha-planta em sistemas agrícolas: forças de interação e nicho tróficos. Dissertação (Mestrado em Zoologia) - Departamento de Ciências Biológicas. Programa de Pós-Graduação em Zoologia. Universidade Estadual de Feira de Santana. Feira de Santana, 2013.

FREITAS, G. S. \& SOARES, A. E. E. Procurando Irá: um passeio ecológico. Ribeirão Preto: Faculdade de Filosofia Ciências e Letras, Faculdade de Medicina de Ribeirão Preto, USP, 2004. 35 p.

LOPES, M. T. R. As abelhas e o clima. Página Rural. 2010. Disponível em: <http://www.paginarural.com.br/artigo/2167/as-abelhas-e-o-clima>. Acesso em: julho 2016.

NUNES-SILVA, P.; HRNCIR, M. \& FONSECA, V. L. I. A polinização por vibração. Oecologia Australis, São Paulo, v. 14, n. 1, p. 140-151, 2010.

OLIVEIRA, P. \& GIMENES, M. Abelhas (Apoidea) Visitantes de Flores de Comolia ovalifolia DC Triana (Melastomataceae) em uma Área de Restinga na Bahia. Neotrop. Entomol., Feira de Santana,v.33, n.3, p.315-320, 2004. 